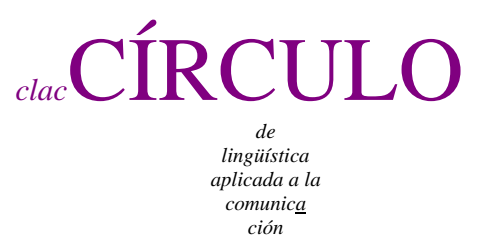

$67 / 2016$

\title{
DIGGING UP THE FREQUENCY OF PHRASAL VERBS IN ENGLISH FOR THE POLICE: THE CASE OF UP
}

\author{
Andreea Rosca and Annalisa Baicchi \\ Universidad de Valencia, Universidad de Pavia \\ andreea rosca at uv es, annalisa baicch at unipv it
}

\begin{abstract}
The present study focuses on the frequency of phrasal verbs with the particle $u p$ in the context of crime and police investigative work. This research emerges from the need to enlarge McCarthy and O’Dell’s (2004) scope from purely criminal behavior to police investigative actions. To do so, we relied on a corpus of 504,124 running words made up of spoken dialogues extracted from the script of the American TV series Castle shown on ABC since 2009. Based on Rudzka-Ostyn's (2003) cognitive motivations for the particle up, we have identified five different meaning extensions for our phrasal verbs. Drawing from these findings, we have designed pedagogical activities for those L2 learners that study English at the Police Academy.
\end{abstract}

Keywords: frequency, phrasal verbs, phrasal-prepositional verbs, cognitive linguistics, English for the Police

Rosca, Andreea, and Annalisa Baicchi. 2016.

Digging up the frequency of phrasal verbs in English for the Police: the case of up. Círculo de Lingüística Aplicada a la Comunicación 67, 273-296.

http://www.ucm.es/info/circulo/no67/rosca.pdf

http://revistas.ucm.es/index.php/CLAC

http://dx.doi.org/10.5209/CLAC.53485

(C) 2016 Andreea Rosca and Annalisa Baicchi

Círculo de Lingüística Aplicada a la Comunicación (clac)

Universidad Complutense de Madrid. ISSN 1576-4737. http://www.ucm.es/info/circulo 


\section{Contents}

1. Introduction 274

2. To be or not to be a phrasal verb: that is the question 276

2.1. Multi-word verbs and tests for phrasal verbs 277

2.2. Approaches to phrasal verbs 280

2.3. Methodology and data retrieval 281

3. Frequency and discussion 284

3.1. Finding meaning extensions 285

3.2. Pedagogical implementation 289

4. Concluding remarks and call for further research 292

References 293

\section{Introduction}

Phrasal verbs constitute a challenging area of English language learning and teaching ${ }^{\mathbf{1}}$. Authors like Sinclair (1989: iv), Trebits (2009), and Alejo et al. (2010) have discussed the factors that influence the avoidance or difficulty of mastering phrasal verbs: (1) the impressive amount of phrasal verbs; (2) the existence of multiple meanings associated with an individual phrasal verb; (3) the structural and syntactic complexity of phrasal verbs (e.g. the transitive/intransitive dichotomy, tense and aspect requirements); (4) cross-linguistic differences (e.g. the absence of phrasal verbs in the learners' mother tongue, Liao and Fukuya, 2004); and (5) poor textbook presentation. Gardner and Davies (2007: 347) confirm the ubiquity of phrasal verbs by stating that "learners will

\footnotetext{
${ }^{1}$ The research on which this paper is based has been financed by the Spanish Ministry of Economy and Competitiveness, grant no. FFI2013-43593-P.
} 
encounter, on average, one [phrasal verb] in every 150 words of English they are exposed to”. Apart from the huge number of English phrasal verbs, native speakers also create new ones with ease and facility (Bolinger, 1971). The sheer number of phrasal verbs may overwhelm L2 learners who are unable to decide which ones to learn. That is why linguists have to establish the usefulness of phrasal verbs in terms of the learners' objectives and learning contexts as well as in terms of their frequency of occurrence. Since the frequency of phrasal verbs is register specific, ESP learners should become familiar with the most common phrasal verbs in their field of study. Furthermore, as pointed out by Biber and Reppen (2002: 200), research findings are not incorporated into language teaching materials and the contents of a syllabus usually rely on "the author's gut-level impressions and anecdotal evidence of how speakers and writers use the language”. Another common criticism leveled against textbook presentation is that it provides learners with overwhelming lists of phrasal verbs together with their corresponding definitions and the practice is usually based on matching or gap-fill exercises (cf. Darwin and Gray, 1999; Gardner and Davies, 2007; Tyler and Evans, 2004). Since phrasal verbs are presented as unanalysable vocabulary items and there is no explicit treatment of the motivated nature of particles, L2 learners are expected to memorize the meanings of phrasal verbs without making any conceptual consideration.

This article aims to examine the frequency of the most productive phrasal verbs with the particle up in the context of crime and police investigative work. This piece of research emerged from the need to address the gaps related to phrasal verbs about police investigative work. McCarthy and O’Dell's (2004) textbook includes phrasal verbs that denote exclusively criminal actions, such as beat sb up, break into/out of sth, hold up $s t h / s b$, put sb up to sth, to name a few. Drawing on a corpus-based analysis, we propose a list of phrasal verbs that also refer to the steps that the police take in the investigation of a crime. Thus, detectives have to look up suspects' criminal history in the database (run sb up), take suspects to the police station in order to be questioned or arrested (pick $s b$ up), obtain more information about something (dig up, follow up on sth), and close an investigation (wrap up a case). To this end, we have built a corpus of spoken dialogues extracted from the script of the American TV series Castle, seasons one to four. Without stage directions, character names, and all incidental language, the size of the corpus is 504,124 running words. For the analysis of phrasal verbs, we have relied 
on Rudzka-Ostyn's (2003) cognitive motivations for the particle up since this approach combines linguistic verbal input with visual images for meaning extensions. Moreover, it has been shown that a CL (Cognitive Linguistics)-based approach to the teaching and learning of phrasal verbs is beneficial in that it facilitates comprehension, retention as well as knowledge transference from learnt to novel phrasal verbs. All these findings have been used to develop pedagogical materials for those L2 learners that study English at the Police Academy.

This article is divided into two different parts. The first part provides the theoretical foundations for our study and the relevant methodological considerations whereas the second part is based entirely on the analysis and explanation of corpora examples as well as the data-driven activities for L2 learners. Section 2 discusses the definition of phrasal verb adopted for the present research. Section 2.1 revises the taxonomy of multi-word verbs and describes the tests used to separate phrasal verbs from other multi-word verbs. In section 2.2 we offer a contrastive examination between traditional and cognitive approaches to phrasal verbs. Section 2.3 describes the procedures that have been followed to compile the data whereas section 3 illustrates the top 25 phrasal verbs with the particle up. Section 3.1 is concerned with the meaning extensions displayed by these phrasal verbs. In section 3.2 we put forward several pedagogical activities intended for English for Police learners. The last section summarizes the findings in our study and proposes future lines of investigation.

2. To be or not to be a phrasal verb: that is the question

The major problem that we face in the study of phrasal verbs is the lack of consensus on what qualifies as a phrasal verb. This issue has been pointed out by Bolinger (1971) who claimed that "being or not being a phrasal verb is a matter of degree” (p. 6). Later on, Gardner and Davies (2007: 341) reinforced the same idea by stating that "linguists and grammarians struggle with nuances of phrasal verb definitions”. In order to avoid ambiguity in the classification of phrasal verbs we are going to use the definition provided by Quirk et al. (1985). According to these authors there are two main criteria that determine what a phrasal verb is, viz. a syntactic and a lexical criterion. Thus, a phrasal verb is a combination between a lexical verb and a morphologically invariable 
particle which functions as a single syntactic unit (p. 1150). Moreover, "the meaning of the combination manifestly cannot be predicted from the meanings of verb and particle in isolation” (p. 1152). Therefore, if the particle is either removed or replaced the lexical verb cannot convey the same meaning. Consider the example The plane touched down where the final meaning 'land' does not derive from the individual meanings of the verb touch or that of the adverbial particle down. This sentence differs greatly from the plane touched or the plane touched downward although the adverbs down and downward can be regarded as synonymous. This non-compositionality is what allows us to distinguish between phrasal verbs and free combinations in which the adverb and the verb preserve their own meaning (e.g. They walked past ['past the object/place]).

Regarding the lexical criterion, Celce-Murcia and Larsen-Freeman (1999) classify phrasal verbs into three semantic categories: literal, idiomatic, and aspectual. In literal phrasal verbs the meaning of the individual components remains unchanged (e.g. put down as in Put the weapon down!). Idiomatic phrasal verbs are characterized by semantic opacity in that the components completely lose their meanings (e.g. make up as 'be reconciled'). On the cline of transparency aspectual phrasal verbs are located between literal and idiomatic phrasal verbs. This is so because the lexical verb has a literal meaning whereas the particle usually adds an opaque meaning about the aspect of the verb. For instance, the adverbial particle up in He finished up the paperwork contributes the idea of completion of an action or process.

\subsection{Multi-word verbs and tests for phrasal verbs}

Both Quirk et al. (1985) and Biber et al. (1999) agree that there are four main types of multi-word verbs, namely phrasal verbs (verb + adverbial particle: pick up), prepositional verbs (verb + preposition: talk about), phrasal-prepositional verbs (verb + particle + preposition: get away with), and other multi-word verb constructions (verb + noun phrase + (preposition): take a look (at); verb +adjective: plead guilty; verb + verb: let (noun phrase) be/go; verb + prepositional phrase: take into account). The first three types of multi-word verbs can also occur as free combinations, where the verb and the adverb/prepositional phrase carry their own distinct meaning. 
Depending on whether phrasal verbs can take a direct object or not, they can be divided into two major subcategories: intransitive (no DO, e.g. When will they give in?) and transitive (with DO, e.g. Find out if they are coming). Some phrasal verbs can be both intransitive and transitive with or without a change in meaning (give in vs. blow up). A prepositional verb is composed of a lexical verb followed by a preposition which is semantically and/or syntactically connected to the verb. Prepositional verbs have two main patterns of complementation: verb + preposition + NP (e.g. We must go into the problem) and verb + NP + preposition + NP (e.g. I accused him of the crime). Phrasalprepositional verbs combine a lexical verb with an adverbial particle and a preposition. There are two main structural patterns for phrasal-prepositional verbs, namely verb+ particle + preposition + NP (e.g. He had to put up with a lot of teasing in school), and verb + NP + particle + preposition + NP (e.g. The manager fobbed me off with a cheap camera).

In what follows we detail what differentiates the first three types of multiword verbs since these were the criteria that we applied to identify phrasal verbs. Based on four comprehensive grammar books (Bolinger 1971; Quirk et al. 1985; Biber et al. 1999; Huddleston and Pullum 2002), we have reviewed and contrasted all the semantic, syntactic and phonological tests for multi-word verbs. Given the space limitations, we will briefly discuss the most recurrent ones, namely replacement, particle movement, adverbial insertion, formation of passives, wh-question formation and stress patterns.

(1) Replacement. According to Bolinger (1971), a verb-particle combination is a phrasal verb if it can be replaced with a single-word verb (e.g. find out $\rightarrow$ discover). However, Biber et al. (1999) stressed that not only phrasal verbs but also prepositional verbs and phrasal-prepositional verb can have single-verb equivalents (e.g. talk about $\rightarrow$ discuss; put up with [such treatment] $\rightarrow$ tolerate [such treatment]). Also, Darwin and Gray (1999) noted that many phrasal verbs cannot be replaced by lexical verbs with a similar meaning (e.g. take over $\rightarrow$ assume control; pay off $\rightarrow$ be worthwhile).

(2) Particle movement. Contrary to prepositional verbs or free combinations, phrasal verbs allow particle movement, i.e. the placement of the particle either before or after the object noun phrase (e.g. She took off the label/She took the label off vs. 
She jumped off the wall/*She jumped the wall off vs. She walked past the office/*She walked the office past). While Celce-Murcia and Larsen-Freeman (1999) noticed that some transitive phrasal verbs do not accept particle movement (e.g. *They came a problem across), Darwin and Gray (1999) showed that this structural change can entail a change in meaning (e.g. I don't want to take on Jill -to hire; I don't want to take Jill on - challenge).

(3) Adverbial insertion. Contrary to prepositional verbs, phrasal verbs do not allow the insertion of an adverb (functioning as an adjunct) between the verb and the particle (e.g. She jumped fearlessly off the wall/*She took carefully off the label). Since sometimes phrasal verbs do accept particle intensifiers like right, straight, and all (e.g. Drink right up/He messed it all up), Darwin and Gray (1999) proposed the insertion of two adverbs ending in -ly (e.g. *I came suddenly and unexpectedly across an old photograph vs. They crept slowly and silently down the hall).

(4) Formation of passives. Palmer (1968) stated that all transitive phrasal verbs can be turned into passives. Nevertheless, Quirk et al. (1985: 1155) showed that some of them do not have a corresponding passive [e.g. The train picked up speed/*Speed was picked up (by the train); Jill and her boss don't hit it off/*It is not hit off (by Jill and her boss)]. What is more, even some prepositional and phrasal-prepositional verbs accept a passive [She was robbed of her necklace (by the gang)/The death penalty has been recently done away with)].

(5) Wh-question formation. This test is useful for distinguishing between prepositional verbs, free combinations and phrasal verbs. Wh-questions for prepositional verbs are usually formed with what or who whereas for free combinations they are formed using the wh-words where and when (e.g. What/who are you waiting for? vs. Where did he run? $\rightarrow$ Up the hill). This test also rules out phrasal verbs which cannot answer where questions (e.g. I looked up the word $\rightarrow$ Where did you look? $\rightarrow *$ Up the word).

(6) Stress patterns. In the case of phrasal verbs the stress falls on the particle whereas in the case of prepositional verbs the stress is placed not on the preposition, but on the lexical verb which is the content word (e.g. He FIGured 
OUT the problem vs. He DEALT with the problem). This test is not without problems since as Bolinger (1971: 14) highlights any word can receive stress in a context where it is either emphasized or contrasted with another one (I said, “What are you looking UP, not what are you looking AT”). Quirk et al. (1985: 1157) also noted that polysyllabic prepositions like across, over, and without are usually stressed (e.g. I could have done withOUT that PRESent).

\subsection{Approaches to phrasal verbs}

In this section we will briefly review and contrast two approaches to phrasal verbs, namely the traditional and the cognitive approaches. We will examine the shortcomings of the traditional perspective and we will motivate our choice of the cognitive perspective.

According to Kovács (2011) the traditional lexico-semantic analyses from the 70s and 80s (Bolinger 1971; Lipka 1972; Fraser 1976) stand in clear opposition to the cognitive perspective (Lindner 1981; Lakoff 1987; Rudzka-Ostyn 2003; Tyler and Evans 2002). Traditional grammarians regard phrasal verbs as arbitrary combinations of a verb and one or more particles. They focus mainly on the syntactic properties of these verbs and highlight the spatial and aspectual meanings of the particles. For example, Fraser (1976: 77) categorically states that particles do not contribute any semantic meaning to phrasal verbs since they have only phonological and syntactic features. According to Lipka (1972) the particle only contributes meaning to the phrasal verb in combinations with semantically empty verbs (e.g. make, do, have, get, give, put). The particle is meaningless in the cases in which the dictionary lists it as optional and in deadjectival verbs (black out).

Contrary to the lack of systematicity in traditional grammar, cognitive grammar pointed out that the meanings of particles in phrasal verbs actually form a network of related senses stretching from literal to metaphorical meanings. The central meaning of a particle refers to spatial locations or movements whereas the peripheral senses which are abstract are usually derived from the concrete, spatial sense "by means of generalization or specialization of meaning or by metonymic or metaphoric transfer" (Cuyckens and Radden, 2002: xiii). CL-inspired proposals shift drastically from the 
traditional approaches in that phrasal verbs are structured around the particle (e.g. down $\rightarrow$ get down, bring down, take down, etc.) rather than the verb (e.g. look $\rightarrow$ look after, look back, look down on, etc.). For example, Tyler and Evans (2002) group the meanings of over in five different clusters of senses: (1) the ABC trajectory (e.g. Sally turned the keys over to the janitor-transfer); (2) the Coverage Schema (e.g. The tablecloth is over the table); (3) the Verticality cluster (e.g. Mary looked over the manuscript quite carefully); (4) the Up cluster (e.g. She has a strange power over mecontrol); and (5) the Reflexive cluster (e.g. After the false-start they started the race over- repetition).

Our research adopts a cognitive perspective since we have used Rudzka-Ostyn's (2003) meaning extensions for the particle up. Despite the traditional techniques used by Rudzka-Ostyn in the practice and testing of phrasal verbs, her presentation is innovative in the sense that it makes use of visual imagery and mental generalization based on linguistic input. The combination of linguistic verbal input with visual images can facilitate the comprehension and retention of phrasal verbs (see Gehring and Toglia, 1989, and Stevick, 1996, for psychological evidence on visualization in education). Finally, the choice of the cognitive perspective is also motivated by the findings put forward by several empirical studies according to which a CL-inspired approach to phrasal verbs can enhance their comprehension and retention (Boers, 2000; Condon, 2008; Condon and Kelly, 2002).

\subsection{Methodology and data retrieval}

As mentioned in the introduction, this study examines the frequency and use of phrasal verbs with up in a criminal context. Basturkmen (2010) has previously stressed out that privacy issues can prevent English for Police course developers from having access to real-life spoken interactions between police officers. That is why we have compiled a corpus made up of spoken dialogues taken from the script of the American TV series Castle shown on ABC since 2009. We have chosen this TV series due to its viewer popularity (approximately 10 to 12 million viewers) not only in the US but also in other European countries like Spain or Italy. The corpus has been stripped of stage directions, 
character names, and all incidental language, leaving a total of 504,124 words of running text ${ }^{2}$.

Building on the work of McCarthy and O’Dell (2004) on phrasal verbs related to crime, in our own research we decided to enlarge the scope from purely criminal actions (beat sb up, hold sth/sb up) and look at how they are used by the police in their investigative work. We divided the phrasal verbs into two categories, namely those related or unrelated to the context of crime, which left us with a total of 519 and 690 tokens respectively. For example, verbs like break up (e.g. We broke up in '82, but we never got over each other [S03E02]), wake up (e.g. When I woke up that morning I just wanted to call you, [...] [S03E03]) or grow up (e.g. You had a lot of imaginary friends growing up, didn't you? [S03E20]) were considered not be connected to the context of crime.

Comprehensive grammar books (Bolinger 1971; Quirk et al. 1985; Biber et al. 1999; Huddleston and Pullum 2002) were used as a reference to identify phrasal verbs. The tests for phrasal verbs listed in these works enabled us to discard free combinations like send up (e.g. They're sending the new guy up now [S02E21]) or bring up (e.g. [...] they brought up the C.S.U. report on the crime scene [S02E21]) where both the lexical verb and the preposition retain their own distinct meaning. Also, their classifications of multi-word verbs proved useful in that they helped us distinguish between phrasal and phrasal-prepositional verbs. Thus, in our corpus we identified 102 phrasal-prepositional verbs unrelated to crime and 60 phrasal-prepositional verbs related to crime. For instance, we have excluded phrasal-prepositional verbs like look up to sb (e.g. And obviously, Alexis looks up to Beckett, and Beckett's smart and strong and independent [S02E09]) or set sb up with sb else (e.g. You know Castle? Jenny's been bugging me to set you up with her cousin Ramona [S04E21]). By contrast, phrasal-prepositional verbs like follow up on sth/sb (e.g. Did you ever follow up on any of those post cards, Detective Smith? [S04E06]) or give up sb to sb else (e.g. Do you think she would give

\footnotetext{
${ }^{2}$ The transcripts for each episode can be found at http://seriesmonitor.com/castle/transcripts/index.html (last accessed May 24th, 2015).
} 
up her friends to the cops? [S01E08]) were regarded as connected to the context of crime and police work.

A special mention should be made of the fact that the phrasal verbs in our corpus are positioned in different places on the cline of prototypicality. Thus, phrasal verbs like beat up (e.g. Making you believe that Knox beat her up so that we'd think she killed him out of self-defense [S02E09]) or lock up (e.g. I'm gonna lock you up as a material witness and send that baby off to foster care [S03E16]) are clearly more prototypical than make up (e.g. That guy does not have the improv skills to make up a lie like that [S03E16]) or get up (e.g. Get up! Put your hands in the air! Hands on your head, now! [S04E15]). This is so because the semantic meaning of the former makes us automatically associate them with the context of crime (e.g. beating up people is not only morally wrong but can cause you to be put in prison). In the case of the latter the connection to crime is cued by the surrounding context (e.g. rendering false testimony is obstruction of justice and the action of standing up is an order given by a policeman to a criminal).

Furthermore, we have noticed that in our corpus the same phrasal verb can be classified either as related or unrelated to crime depending on the nature of the affected entity (direct object). Take for example a verb like clean up which means 'to make a place tidy’. In the sentence No, I cooked. Someone else cleans up [S02E16] we know by common sense that what is cleaned is the dishes and that the context has nothing to do with crime (the situation refers to a family dinner). Consider now a different sentence More like the family fixer. He cleaned up all types of dirt for Senator Wellesley back in the day [S02E08]. The same phrasal verb refers to a criminal context in which an Agent cleans a crime scene making sure not to leave evidence behind. Another less prototypical meaning for clean up is 'to stop using drugs' as in Alison King Rehab Center. It's where all the stars go to clean up [S02E07].

As seen from these fine-grained distinctions counting the frequency of phrasal verbs can be a rather challenging task. We have chosen to go through the examples one by one to ensure the accuracy and reliability of the data. Finally, watching the episodes has enabled us to contextualize the data, spot potential mistakes and reclassify phrasal verbs. 


\section{Frequency and discussion}

Table 1 lists the 25 most productive phrasal verbs with the particle up in our corpus. Their frequency of occurrence is displayed both in raw numbers and percentages together with the cumulative counts. As mentioned in the methodological section, we have found a total of 519 phrasal verbs related to the context of crime and police investigative work. We have also identified a total of 100 lexical verb-types for this particle. The cumulative percentages in the table below indicate that the top 11 phrasal verbs constitute more than $50 \%$ of all phrasal verbs in our corpus.

Interestingly enough, eight of these phrasal verbs are also listed among the top 25 phrasal verbs in the COCA (cf. Liu 2011; e.g. pick up, come up, set up, give up, make up, end up, look up, and get up). Other fifteen phrasal verbs that were encountered in our corpus were also found among the 150 most frequent phrasal verbs in the COCA (e.g. show up, hold up, put up, bring up, open up, keep up, pull up, clean up, wind up, turn up, back up, blow up, shut up, move up, follow up). As already pointed out by Trebits (2009), ESP course designers and materials developers should be more concerned with those phrasal verbs that are frequent in the ESP field but not so much in general English. In our case, English textbooks designed for the Civil Guard or the National Police Corps should put special emphasis on phrasal verbs such as beat up, break up [fight], cover up, dig up, lock up, lawyer up or write up.

Table 1 . The top 25 phrasal verbs with the particle up in the corpus

\begin{tabular}{|l|l|l|l|l|}
\hline Rank & PV & Raw frequency & $\begin{array}{l}\text { \% of all PVs with up in } \\
\text { the corpus }\end{array}$ & Cumulative \% \\
\hline 1 & end up & 63 & 12.13 & 12.13 \\
\hline 2 & pick up & 53 & 10.21 & 22.35 \\
\hline 3 & set up & 24 & 4.62 & 26.97 \\
\hline 4 & turn up & 20 & 3.85 & 30.82 \\
\hline 5 & open up & 19 & 3.66 & 34.48 \\
\hline 6 & cover up & 18 & 3.46 & 37.95 \\
\hline 7 & come up & 17 & 3.27 & 41.23 \\
\hline 8 & give up & 15 & 2.89 & 44.12 \\
\hline 9 & dig up & 14 & 2.69 & 46.82 \\
\hline
\end{tabular}




\begin{tabular}{|l|l|l|l|l|}
\hline 10 & make up & 13 & 2.50 & 49.32 \\
\hline 11 & blow up & 12 & 2.31 & 51.63 \\
\hline 12 & clean up & 11 & 2.11 & 53.75 \\
\hline 13 & beat up & 10 & 1.92 & 55.68 \\
\hline 14 & lock up & 10 & 1.92 & 57.61 \\
\hline 15 & pull up & 10 & 1.92 & 59.53 \\
\hline 16 & look up & 8 & 1.54 & 61.07 \\
\hline 17 & show up & 8 & 1.54 & 62.62 \\
\hline 18 & shut up & 8 & 1.54 & 64.16 \\
\hline 19 & call up & 7 & 1.34 & 65.51 \\
\hline 20 & follow up & 7 & 1.34 & 66.85 \\
\hline 21 & get up & 7 & 1.34 & 68.20 \\
\hline 22 & lawyer up & 7 & 1.34 & 69.55 \\
\hline 23 & screw up & 7 & 1.34 & 70.90 \\
\hline 24 & write up & 7 & 1.34 & 72.25 \\
\hline 25 & break up & 6 & 1.15 & 73.41 \\
\hline
\end{tabular}

It is worth recalling that we have also identified 60 tokens of phrasal-prepositional verbs and a total of 27 lexical verb-types. Since they are not as frequent as phrasal verbs we will only enumerate the top 10 (e.g. come up with sth, clean up after oneself, follow up on sth/sb, dig up sth on sb, lead up to sth, back sb up on sth, catch up with sb, follow up with $s b$, give up sb to sb else, live up to sth). As can be seen, the most recurrent phrasalprepositional verbs in our corpus are usually combinations between the most productive phrasal verbs (e.g. come up, clean up, follow up, give up, dig up) and other prepositions (e.g. with, after, on, to).

\subsection{Finding meaning extensions}

After counting the tokens and verb-types, we have followed Rudzka-Ostyn's (2003) cognitive motivations to pinpoint the literal and metaphorical meaning extensions of the particle up in our corpus. Thus, we have come up with the following clusters: 
(1) UP: position at a high place or moving up to a higher one - dig up (literal meaning), put (entity) up, get up, keep (hands) up, stand up, mount up, saddle up

(2) UP (to): aiming at or reaching a goal, an end, a limit - back up, lead up to sth, go up against (lack of connectivity), catch up with sb, hook sb up, line up with sth, match up sth with sth else, follow up, give up (an activity), fill up, give sb up to $s b$ else (deliver to authorities), hit up, pick up, grab up, snatch up, lock up, live up to sth

(3) UP: moving to a higher degree, value or measure - blow up (enlarge picture), change up, switch up, shore up, back up, stack up, pile up, shoot up (drugs), mob up, offer up, dirty up, straighten up, lawyer up, spark up, gather up (crew), partner up

(4) UP: higher up is more visible, accessible, known - show up, turn up, pop up, bring up (issue), bring up (on a screen), come up (appear), come up with sth, call sth up (screen), pull up (screen), give up (information), throw up (red flags), dig up (info), dredge up, kick up, stir up, look up, run up, read up on sb, study up on sb, chat up, size up, clear up, mock up, draw up (document), write up, set sb up (bring about a bad situation for sb, make him become a suspect), round up, rig up, cook up (drugs), make up (falsify)

(5) UP: covering an area completely/reaching the highest limit- blow up (explode), dress up, clean up, cover up, stir up (crime scene-destroy), tear up, bust up, bang up, hack up, cut up, slice up, beat up, break up (fight), screw up, mess up, bollix up, wipe up, mix sb up with sb else, wrap up (case), seal up, tie up, tangle up, pack up, sew up, package up, check up, tune up, wind up, turn up (dead), end up, show up (murdered), open up, shut up, hole up, tape up, wrap up (dead body), pay up, hold up, tense up, freeze up, fill up (cell), finish up, divvy up

Let us exemplify these five meaning extensions by focusing on some phrasal verbs from the ones that we have enumerated above. The first semantic extension is also the central meaning conveyed by the particle up, namely literal motion from a lower to a higher place. This meaning extension is evoked by a phrasal verb like put up which, among others, can mean 'to raise something or to fix something in a raised position’ (e.g. Put your hands up, Dunn, or I will take you down [S02E18]). The 
second semantic extension denotes either literal or abstract motion towards a goal or limit where the goal can be extended to situations, habits and emotional states (e.g. In the months leading up to her death, Cynthia was working with a journalist [S01E08]). The particle up can also be used to express abstract motion to a higher degree, value or measure. In the sentence That's a serious allegation. Do you have any proof to back it up? [S04E13] the phrasal verb back up indicates that evidence can lend further credence to a claim on the scale of truth and falsity. Another meaning extension associated with the particle up is greater visibility, access to knowledge or the action of appearing since an entity that is located or comes to a higher level or location is noticed more easily (e.g. Contusions coming up, here and here. But it's likely a result of his tumble down the trash chute [S02E10]). The last meaning extension, i.e. covering an area completely or reaching the highest limit, gathers the phrasal verbs related to the idea of completing or finishing something (e.g. Getting that body was supposed to sew our case up, not blow it apart. How could those bullets not match? [S04E03]), damaging and destroying (e.g. Why would Bobby go see a comedian who didn't want to do his show and then bust up her bike? [S02E20]), stopping, delaying and disrupting (e.g. Breaking up a bar fight is a sure way to get hit [S02E09]) and dividing or separating (e.g. A masked vigilante on the loose hacking people up [S04E02]).

As far as the number of meanings is concerned, it is interesting to note that the most frequent phrasal verbs in our corpus are also the most polysemous. Consider for instance the phrasal verb pick up which can have five different meanings: (1) stop and take someone to a police station in order to be questioned or arrested (e.g. Police picked him up in Atlantic City for charges of disorderly conduct [S02E23]); (2) collect something, usually in an illegal transaction (e.g. Only Benny makes off with the money before the blackmailer's had a chance to pick it up [S02E23]); (3) make a place clean and tidy (e.g. It takes real presence of mind to put five bullets into a man's chest and then keep your cool long enough to pick up after yourself [S02E24]); (4) capture on film (e.g. We just got word on the security footage at the airport. Cameras did pick up a blue, late model Malibu leaving the area but its license plate was blacked out [S03E24]); and (5) notice a smell or sound, or to 
notice that someone or something is present (e.g. Dogs picked up a scent, traced it to the west side of the cemetery, but then they lost it there [S04E01]).

In our corpus we have found some phrasal verbs that can also function as copular verbs. A case in point is the phrasal verb come up which can combine with various adjectives to convey both related and different meanings: (1) with empty- fail to achieve a desired result (e.g. But we've run the prints and we still came up empty. No matches to anyone at The Old Haunt or in our system [S03E10]); (2) with shortfail to meet expectations (e.g. Just thinking about Burns and how close he came to catching the guy who killed his daughter only to come up short [S03E20]); (3) with negative- bring about a negative result (e.g. And a forensics sweep of the water tank came up negative for any prints on the operating apparatus other than Zalman's [S03E12]); and (4) with clean- exonerate a suspect (e.g. I ran the pet shop owner Noel Du Preez, he came up clean [S02E14]). Other phrasal verbs that act as copular verbs are end up (e.g. How do a blackmailer and his victim both end up dead? [S03E23]), show up (e.g. You vowed revenge, and then Hixton shows up dead with witnesses claiming to see you at the crime scene? [S03E14]), turn up (e.g. You left the party the same time that Derek left, and then he turned up dead [S03E07]), and wind up (e.g. Heading to meet his fiancée at a cake shop in Great Neck, how'd he wind up dead on a street in Harlem? [S01E10]).

Finally, we would like to point out that some phrasal verbs are closely related in meaning and almost interchangeable in certain contexts. Take for instance the verbs kick up and stir up which are used with the meaning 'create trouble' (Mr. Wellesley, we are going to find out the truth. And the amount of dust that we kick up doing that is entirely up to you [S02E08]; We're just gonna knock on doors and see what else we can stir up [S02E01]). Other similar cases would be dig up and dredge up meaning 'unearth evidence', show up, turn up, and pop up meaning 'appear', or grab up, pick up, and snatch up meaning 'arrest or take to the police station for interrogation'. 


\subsection{Pedagogical implementation}

On the basis of the findings discussed in the previous sections we propose an outline of possible teaching activities that English for Police teachers could use in their classes. Teachers can choose from a rich gamut of strategies: (1) inductive instruction which requires learners to infer the meaning of a phrasal verb out of and from context (i.e. concordance lines from a corpus), (2) deductive instruction during which learners are exposed to explicit explanations about the systematicity of phrasal verbs in the context of crime and police investigation, and (3) communicative approach which requires learners to discuss in pairs or groups the scenarios evoked by phrasal verbs (e.g. searching for evidence, arresting, negotiating with criminals), to work out together the connections between different meaning extensions, to create a dialogue incorporating phrasal verbs and perform it in front of the class.

\section{INDUCTIVE INSTRUCTION}

(a) In groups of three try to predict all possible meanings of the following phrasal verbs: end up, pick up, and set up. Can you think of any literal/spatial or figurative/metaphorical meanings for these phrasal verbs in the context of crime and police investigative work?

(b) Next, compare your group predictions with the uses found in the concordance lines listed below. Identify the literal and the figurative meanings of these phrasal verbs.

1. And so she follows Sophie to her room and confronts her. And when things get violent, Sophie ends up dead. [S02E12]

2. Then how did her earring end up in your room? [S02E12]

3. Sounds like Donny was late with his hundred and fifty grand for Billy Pitt and he ended up paying for it with his life.[S03E10]

4. We got picked up for public intoxication. My father got the charges dropped, but, uh, there's still a record of our arrest. If you can't find it, I have a framed copy at home. [S02E08]

5. I used the library computer and Zack's e-mail account. I e-mailed Brian saying I had his 'roids and I was going to rat him out unless he put 25 grand into a paper bag and left it underneath the bench at the quad. When the coast was clear, I picked it up. I never meant for anyone to get hurt. I'd like that phone call now. 
6. I thought you said Zack wasn't using steroids.

\section{LANIE}

The tests wouldn't pick up stuff like this [S03E21]

7. Whatever the complaint is, I'm gonna need the two of you to pick it up first thing in the morning.

8. When I heard the noises coming from the next room I thought maybe whoever killed her was coming back. So I picked up the gun to defend myself [S03E01]

9. We just got word on the security footage at the airport. Cameras did pick up a blue, late model Malibu leaving the area but its license plate was blacked out. [S03E24]

10. Dogs picked up a scent, traced it to the west side of the cemetery, but then they lost it there. [S04E01]

11. It takes real presence of mind to put five bullets into a man's chest and then keep your cool long enough to pick up after yourself. [S02E24]

12. Detective. Don't you get it? My own people are setting me up. And they're not going to stop until I'm dead. [S04E16]

13. Get the duty roster from the prison. See who was working when Brady made his calls. Set up a protection detail for the wife and the kid. [S02E08]

14. Castle and I will set up at the paper in case he shows up. [S02E14]

(c) By checking the concordance lines above, specify the aspects these phrasal verbs relate to, namely evidence (emergence/compilation/elimination), criminal behavior and police actions. Complete the table with your findings.

\begin{tabular}{|l|l|l|}
\hline Evidence & Criminal behavior & Police actions \\
\hline $\begin{array}{l}\text { end up- finally be in an } \\
\text { incriminating place }\end{array}$ & $\begin{array}{l}\text { set sb up - frame a pick sb up - arrest } \\
\text { person }\end{array}$ & \\
\hline & & \\
\hline & & \\
\hline & & \\
\hline
\end{tabular}


Students are provided with explicit explanations of the cognitive motivations for the particle up in English. The verbal explanations should be combined with Rudzka's visual images for the meaning extensions (see diagram below). The explicit presentation is then followed by practice applying the rule.

A phrasal verb is made up of a verb and a particle (e.g. pick up). Their combination usually changes the meanings that the verb and the particle might have separately. Particles can have literal or spatial meanings and figurative or metaphorical meanings. The literal meaning is considered as the basic/central meaning whereas the figurative meanings are extensions of the basic meaning. 1) For example, the basic meaning of the particle up is spatial movement of an entity from a lower to a higher place. In example 8 (pick up the gun), the suspect is lifting the murder weapon from the ground to the eye-level. 2) The lower place is the starting point or source whereas the higher place is the destination. Locations can be either concrete (e.g. shelf, table) or abstract (status/rank). Take for instance the sentence In the months leading up to her death, Cynthia was working with a journalist [S01E08]. In this sentence you can notice a figurative meaning of the particle up: non-literal motion towards an abstract destination. Life is understood as literal motion on a path, temporal events as different points on the path and death as the final destination (goal/limit of motion). 3) Changes are also perceived as literal upward/downward motion on a vertical scale. Consider the sentence Can you blow up this one section [of the picture]? [S04E20]. Enlargement of the dimensions of a picture is seen as gradual upward motion on the scale of size. 4) When an entity moves to a higher location it is easier to be noticed. Take the following example [...] they're going to dig up everything they can on the owner, it could be that he is hiding something [S02E14]. In this context, police investigations cause secret facts about a suspect's life to become known (visible figuratively). 5) The particle up can also indicate that the object is completely affected by an action. In the sentence You provided him with enough C4 to blow up half a city block [S03E12] the explosive completely destroys the affected entity (half a city block). 
Rudzka's meaning extensions for the particle UP

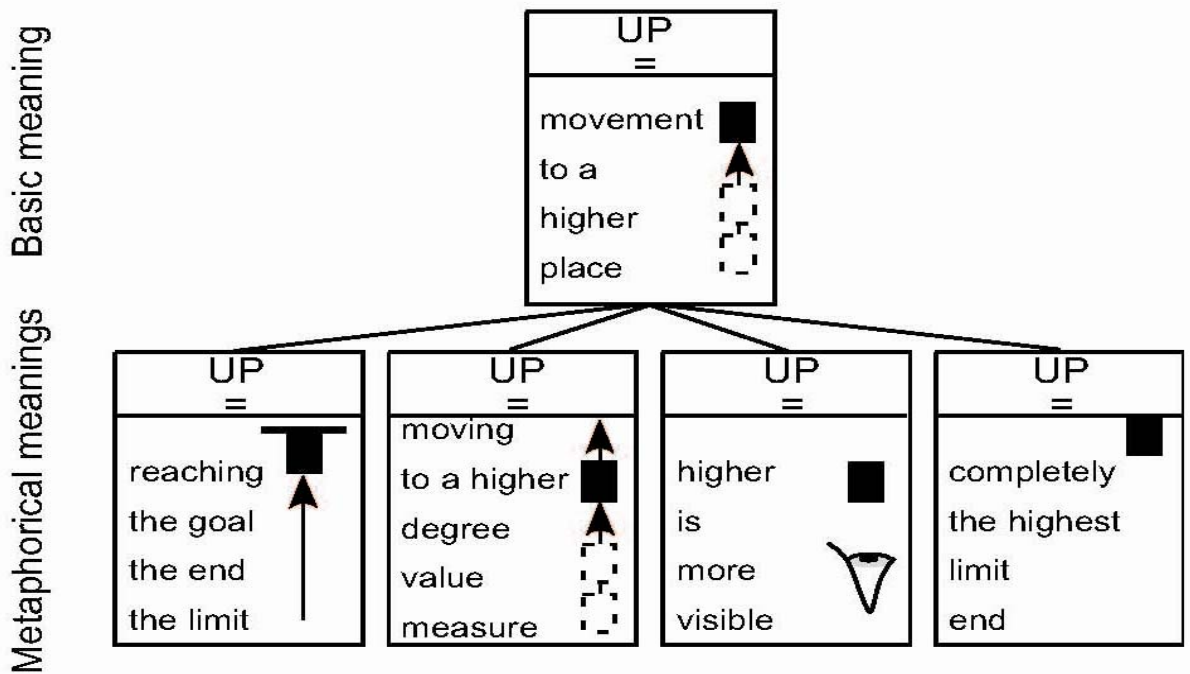

(3)

INDIVIDUAL PRACTICE AND PAIRWORK

Now, go back to the previous examples (1-14) and try to classify them according to Rudzka's meaning extensions. Write a detailed explanation why you think this is so. Then, discuss your considerations with your shoulder partner.

ORAL INTERACTION

Together with your face partner make up a ten-line dialogue using at least 5 phrasal verbs from the ones that you have come across so far. Then, act out the dialogue in front of the class.

\section{Concluding remarks and call for further research}

To sum up, our research contributes to the field of English for Specific Purposes (viz. English for the Police) in that it establishes the usefulness of phrasal verbs related to crime based on their frequency of occurrence. It has also enlarged McCarthy and O'Dell's (2004) perspective on phrasal verbs around the theme of crime in that it includes phrasal verbs that indicate not only criminal actions but also actions carried out by the police. It has shown that phrasal verbs represent a multi-faceted word class in the sense that the same phrasal verb can be conceptualized as related or unrelated to the context of crime (e.g. clean up). We have also made a clear distinction between purely phrasal verbs (e.g. follow up) and phrasal-prepositional verbs (e.g. follow up on sth/sb, 
follow up with sb). Furthermore, we have used Rudzka-Ostyn's (2003) meaning extensions for the particle up to illustrate how the meanings of the phrasal verbs in our corpus range from literal (e.g. physical motion from a lower to a higher position, put up) to figurative ones (e.g. abstract motion from a lower to a higher degree, value or measure, back up). We have also pointed out that certain phrasal verbs have a similar meaning which allows them to become almost interchangeable. Some of them also function as copular verbs, e.g. end up (dead) and wind up (dead). Last but not least, we have designed pedagogical activities on the basis of our research findings by combining inductive, deductive and communicative approaches to language learning and teaching.

Several suggestions could be taken into consideration for the future development of this research. First, we should also examine the frequency of phrasal verbs with the opposing particle down, as well as other contrasting pairs, such as out and in, on and off, among others. This kind of analysis would help English for Police students have a more global picture of the most productive phrasal verbs in the context of crime and police investigative work. Second, we should test the validity of our findings against other major varieties of English, such as British English. Lastly, this CL-inspired approach to phrasal verbs should be incorporated into a language learning program to verify the learning gains of such pedagogy and see whether students transfer their knowledge of CL motivations to novel phrasal verbs used in the same context.

\section{References}

Alejo González, Rafael, Ana Piquer Píriz and Guadalupe Reveriego Sierra, 2010: "Phrasal verbs in EFL course books" in Sabine De Knop, Frank Boers and Antoon De Rycker (eds.): Fostering Language Teaching Efficiency through Cognitive Linguistics, Berlin/New York: Mouton de Gruyter, 59-78.

Basturkmen, Helen, 2010: Developing courses in English for specific purposes, London: Palgrave Macmillan, 71-87.

Biber, Douglas, et al., 1999: Longman Grammar of Spoken and Written English. London: Longman.

Biber, Douglas and Randi Reppen, 2002: "What does frequency have to do with grammar teaching?”, SSLA 24, 199-208. 
Boers, Frank, 2000: "Metaphor awareness and vocabulary retention”, Applied Linguistics 21, 553-571.

Bolinger, Dwight, 1971: The Phrasal Verb in English. Cambridge, Massachusetts: Harvard University Press, 99-104.

Celce-Murcia, Marianne, and Diane Larsen-Freeman, 1999: The grammar book: An ESL/EFL teacher's course (2nd ed.), Boston: Heinle and Heinle.

Condon, Nora, and Peter Kelly, 2002: “Does Cognitive Linguistics have anything to offer English language learners in their efforts to master phrasal verbs?”, I.T.L.137-138, 205-231.

Condon, Nora, 2008: "How cognitive linguistic motivations influence the learning of phrasal verbs” in Frank Boers, and Seth Lindstromberg (eds.): Cognitive Linguistic Approaches to Teaching Vocabulary and Phraseology, Berlin: Mouton de Gruyter, 133-158.

Darwin, Clay, and Loretta Gray, 1999: “Going After the Phrasal Verb: An Alternative Approach to Classification”, Tesol Quarterly 33(1), 65-83.

Fraser, Bruce, 1976: The Verb-Particle Combination in English, New York: Academic Press.

Gardner, Dee, and Mark Davies, 2007: “Pointing Out Frequent Phrasal Verbs: A Corpus-Based Analysis”, Tesol Quarterly 41(2), 339-359.

Gehring, Robert, and Michael Toglia, 1989: "Recall of pictorial enactments and verbal descriptions with verbal and imagery study strategies”, Journal of Mental Imagery 13(2), 83-98.

Huddleston, Rodney, and Geoffrey Pullum, 2002: The Cambridge Grammar of the English Language, Cambridge: Cambridge University Press.

Kovács, Éva, 2011: “The traditional vs. cognitive approach to English phrasal verbs” [http://www.uni-miskolc.hu/ philos/2011_tom_XVI_1/141.pdf, last accessed: 24th of May, 2015].

Lakoff, George, 1987: Women, Fire and Dangerous Things: What Categories Reveal about the Mind, Chicago and London: The University of Chicago Press, 418-439. 
Liao, Yan, and Yoshinori Fukuya, 2004: “Avoidance of Phrasal Verbs: The Case of Chinese Learners of English”, Language Learning 54(2), 193-226.

Lindner, Susan, 1981: A Lexico-Semantic Analysis of English Verb Particle Constructions with OUT and UP. Ph. D. diss, University of California in San Diego.

Lipka, Leonard, 1972: Semantic Structure and Word-Formation. Verb-Particle Constructions in Contemporary English, München: Wilhelm Fink Verlag.

Liu, Dilin, 2011: “The Most Frequently Used English Phrasal Verbs in American and British English: A Multicorpus Examination”, Tesol Quarterly 45(4), 661-688.

Mccarthy, Michael, and Felicity O’Dell, 2004: English phrasal verbs in use, Cambridge: Cambridge University Press.

Quirk, Randolph, et al., 1985: A comprehensive grammar of the English Language. London and New York: Longman.

Palmer, Frank, 1968: A linguistic study of the English verb, Coral Gables, FL: University of Miami Press.

Rudzka-Ostyn, Brygida, 2003: Word Power: Phrasal Verbs and Compounds, The Hague: Mouton de Gruyter.

Sinclair, John (ed.), 1989: Collins Cobuild Dictionary of Phrasal Verbs, London: Collins Publishers.

Trebits, Anna, 2009. "The most frequent phrasal verbs in English language EU documents-A corpus-based analysis and its implications”, System 37, 470-481.

Stevick, Earl, 1996: Memory, Meaning and Method: A View of Language Teaching (2nd Edition), Boston, MA: Heinle and Heinle Publishers.

Tyler, Andrea, and Vyvyan Evans, 2002: Spatial Scenes: A Cognitive Approach to Prepositions and the Experiential Basis of Meaning, Cambridge: Cambridge University Press. 
Tyler, Andrea, and Vyvyan Evans, 2004: “Applying cognitive linguistics to pedagogical grammar: The case of over" in Michel Achard and Susanne Niemeier (eds.), Cognitive linguistics, second language acquisition, and foreign language teaching, Berlin: Mouton de Gruyter, 257-280.

Received: June 11, 2015

Accepted: July 2, 2016

Published: September 23, 2016 